ISSN 1981-416X

Licenciado sob uma Licença Creative Commons

\title{
Potencialidade do Google Maps nas aulas de Geografia em uma escola do campo
}

\author{
Potentiality of Google Maps in Geography \\ classes in from rural school
}

Potencialidad de Google Maps en las clases
de Geografía en una escuela del campo

\section{Liziany Müller Medeiros ${ }^{[a]}$, Valquira Conti ${ }^{[a]}$, Janete Webler Cancelier ${ }^{[a][b]}$, Juliane Paprosqui Marchi da Silva ${ }^{[a][b]}$, Paulo Roberto Colusso ${ }^{[a] b]]^{*}}$}

\author{
[a] Universidade Federal de Santa Maria, Santa Maria, RS, Brasil \\ [b] Universidade Aberta do Brasil, Santa Maria,RS, Brasil
}

\section{Resumo}

O presente artigo tem como objetivo avaliar as potencialidades do uso da ferramenta Google Maps para o ensino de Geografia em uma Escola Estadual de Ensino Fundamental, localizada no município de Santa Maria, RS, Brasil. A pesquisa pretendeu apresentar a ferramenta Google Maps para educandos, ensinando suas funções e identificando através da ferramenta o espaço onde estes jovens e a escola em que estudam se insere, também buscou avaliar se a ferramenta auxilia na democratização do conhecimento no que tange

\footnotetext{
"LMM: Doutora em Agronomia, e-mail: lizianym@hotmail.com VC: Mestre em Geografia, e-mail vauconti@hotmail.com JWC: Doutora em Geografia, e-mail: janetewc@yahoo.com.br JPMS: Mestre em Tecnologias Educacionais em Rede, e-mail: juliane_paprosqui@hotmail.com PRC: Mestre em Engenharia da Produção, e-mail: prcolusso@cead.ufsm.br
} 
à geografia escolar. A pesquisa trata-se de um estudo de caso com abordagem qualitativa. Para tanto, foram realizadas atividades, relativas a conteúdos que abordam problemas ambientais. Através da utilização do Google Maps, os educandos relataram que a ferramenta proporcionou uma aprendizagem mais dinâmica e interativa, uma vez que o mesmo aproveita os conhecimentos prévios de cada um, levando-os a relacionar os conhecimentos adquiridos com o seu cotidiano e tornando mais fácil o entendimento de conceitos mais específicos, potencializando, assim, o ensino facilitado pelas tecnologias digitais da informação e comunicação (TDIC) e democratizando o conhecimento.

Palavras-chave: Google Maps. Educação do Campo. Ensino de Geografia.Tecnologias de informação e comunicação.

\begin{abstract}
This article aims to evaluate Google Maps's usage potential for the teaching of Geography at the Arroio Grande State School of Elementary Education. As specific objectives, the research intends to present the Google Maps tool for learners of the State School of Elementary Education Arroio Grande, teaching their functions; identify through the Google Maps tool the space where these young people and the school in which they study is inserted; evaluate whether the tool assists in the democratization of knowledge regarding school geography. The research is a case study with a qualitative approach. For that, activities were carried out, with students of Basic Education, using Google Maps as a tool for interaction and complementation of the content Environmental Problems. Through the use of Google Maps, the students reported that the tool provides a more dynamic and interactive learning, since it takes advantage of the previous knowledge of the students, leading them to relate the knowledge acquired with their daily life and making it easier to understanding of more specific concepts, thus enhancing teaching and democratizing knowledge.
\end{abstract}

Keywords: Google Maps. Field Education. Geography Teaching. Information and Communication Technologies. 


\section{Resumen}

El presente artículo tiene como objetivo evaluar las potencialidades del uso de la herramienta Google Maps para la enseñanza de Geografía en una Escuela Estatal de Enseñanza Fundamental ubicada en el municipio de Santa Maria RS. La investigación pretendió presentar la herramienta Google Maps para educandos, enseñando sus funciones e identificando a través de la herramienta el espacio donde estos jóvenes y la escuela en que estudian se inserta, también buscó evaluar si la herramienta auxilia en la democratización del conocimiento en lo que se refiere a la geografía escolar. La investigación se trata de un estudio de caso con un enfoque cualitativo. Para ello, se realizaron actividades, relativas a contenidos que abordan problemas ambientales. A través de la utilización de Google Maps, los educandos relataron que la herramienta proporcionó un aprendizaje más dinámico e interactivo, ya que el mismo aprovecha los conocimientos previos de cada uno, llevándolos a relacionar los conocimientos adquiridos con su cotidiano y haciendo más fácil el entendimiento de conceptos más específicos, potenciando así la enseñanza facilitada por las tecnologías digitales de la información y comunicación (TDIC) y democratizando el conocimiento.

Palabras clave: Google Maps. Educación del Campo. Enseñanza de geografía. Tecnologías de información y comunicación.

\section{Introdução}

O uso das Tecnologias Digitais de Informação e Comunicação (TDIC) na área da educação estão cada vez mais presentes na realidade das escolas. Tais tecnologias são importantes, pois permitem uma nova forma de pensar no desenvolvimento do ensino, contribuindo para uma nova metodologia que oriente a construção do conhecimento, conforme afirma Sacramento e Munhoz (2009). A tendência deste uso permite que as aulas se tornem diferenciadas, potencializando o processo de ensino-aprendizagem dos educandos.

Na disciplina de Geografia, muitos recursos podem ser utilizados, dentre eles a ferramenta Google Maps, que se apresenta como uma ferramenta do Google para visualização de mapas e imagens gratuitas 
feitas por satélite. Esta plataforma é um importante recurso para trabalhar conteúdos relacionados à cartografia, pois permite ter uma visão completa sobre o lugar a ser estudado.

O uso da tecnologia nas escolas ainda se configura como um desafio a ser superado. Pouco a pouco, com o auxílio de políticas públicas, formações continuadas e ferramentas educacionais, esse quadro começa a se alterar. Esses desafios estão ainda mais presentes quando se trata de escolas marginalizadas pelo acesso às Tecnologias de Informação e Comunicação, como escolas de periferia e escolas do campo ${ }^{1}$.

Acredita-se que, nas escolas do campo, as práticas pedagógicas mediadas pelas inovações tecnológicas são menos difundidas que em áreas urbanas, como afirma Vighi (2013). Neste sentido, é importante estabelecer a interação do uso destas tecnologias com a realidade dos educandos do campo, os quais também demandam da necessidade dessa interação.

Segundo Molina e Sá (2012, p. 326) “a Educação do Campo surge a partir da luta dos movimentos sociais camponeses por terra e por educação". Caldart (2012, p. 257) ainda acrescenta que a Educação do Campo "nomeia um fenômeno da realidade brasileira atual, protagonizado pelos trabalhadores do campo".

As trajetórias de vida, bem como os saberes tradicionais dos sujeitos do campo, são fundamentais para no cotidiano das escolas do campo. Esta perspectiva trabalha com o intuito de que a maneira de ser e de viver desses grupos sociais se mantenham vivas, trabalhando a ideia de identidade destes sujeitos.

A educação do campo, em sua raiz epistemológica, segundo Medeiros e Cabral (2006), traz o viés de formar cidadãos críticos, capazes de compreender seu papel como atores sociais, identificando-se no lugar onde estão inseridos. Para entender melhor o lugar onde os educandos se inserem, a cartografia se mostra como um excelente meio, visto que a partir deste recurso, é possível conhecer o espaço geográfico sem sair da sala de aula (DAMBRÓs, 2014).

1 Vale ressaltar que nem todas as escolas de periferia ou do campo estão à margem deste processo. 
Neste contexto, se faz de grande valia o desenvolvimento de noções cartográficas para com os educandos, com o intuito de que eles, como afirma Dambrós (2014, p. 15) "percebam o espaço geográfico como um produto histórico, fruto das inúmeras transformações ocorridas ao longo do tempo".

Em meio à temática da cartografia, muitos assuntos podem ser abordados. Partindo de uma demanda mencionada pela escola, optou-se por seguir um viés ambiental, trabalhando com os educandos sobre a preservação ambiental, com enfoque na mata ciliar e nos rios que escoam próximos da escola.

Dessa forma, é importante que a Geografia auxilie os educandos na compreensão das interações entre a sociedade e natureza desde a educação infantil. Neste contexto, conhecer sobre a cartografia e orientação espacial se mostra de grande valia para a compreensão de diversos fenômenos, dentre eles a localização espacial da escola, da comunidade e do ambiente que os circunda.

Segundo Dambrós (2014, p. 16), ao reconhecer e entender o modo como o espaço se organiza a partir da leitura de um mapa, o educando pode "adquirir um olhar crítico frente à realidade, obtendo autonomia no pensar e tornando-se agente transformador do seu ambiente de vivência". Para tanto, a alfabetização cartográfica se mostra importante, pois, ensina a ler o espaço que está sendo apresentado ao educando.

O programa Google Maps pode ser utilizado como recurso didático pedagógico para elaboração de representações do espaço de vivência do educando, despertando seu interesse e a curiosidade para o aprendizado de cartografia. Segundo Cirolini (2008), o uso das funções da ferramenta para o ensino de cartografia permite ao educando interagir com o espaço a ser representado e, assim, ser usuário, leitor, produtor e comunicador de informações a respeito da realidade em que vive, contribuindo dessa forma na (re) construção da identidade do lugar onde ele se insere, bem como potencializando a democratização do conhecimento.

A partir dessas premissas, busca-se compreender a seguinte questão: quais as potencialidades do uso da ferramenta Google Maps para o ensino de Geografia em uma escola do campo? Justifica-se a importância 
da presente pesquisa visto a insipiência de trabalhos voltados para as TDIC em escolas do campo.

Assim, de modo geral, objetiva-se avaliar as potencialidades do uso da ferramenta Google Maps para o ensino de Geografia na Escola Estadual de Ensino Fundamental Arroio Grande, localizada no município de Santa Maria RS. Como objetivos específicos, a pesquisa pretendeu apresentar a ferramenta Google Maps para educandos, ensinando suas funções; identificando o espaço onde estes jovens e a escola em que estudam se insere; avaliar se a ferramenta auxilia na democratização do conhecimento no que tange àgeografia escolar.

\section{Educação do campo e TICs}

Segundo Leão (1999) a Educação, tanto a brasileira quanto a mundial, vêm passando por uma intensa mudança de paradigmas. Para a referida autora, anteriormente a educação estava baseada em uma perspectiva de ensino tradicional e voltada para as práticas passivas de ensino aprendizagem. Atualmente, vivencia-se a emergência de um processo inovador no ensino, inserindo novas formas de mediação do conhecimento para os educandos (PERIN, 2013).

Neste sentido, Perin (2013) afirma que é possível visualizar no cenário contemporâneo a passagem de uma ação pedagógica baseada no quadro de giz e nos livros didáticos, de natureza vertical na relação educador - educando para uma perspectiva baseada na mobilização do conhecimento disponibilizado nos meios midiáticos. A revolução nas potencialidades de comunicação digital permite que os educadores e educandos, em relação mais igualitária, possam acessar o conhecimento já produzido.

Cancela (2012) reconhece que os educandos também detêm importantes conhecimentos e que, cada vez mais, seu domínio sobre as tecnologias de informação e comunicação os coloca diante de uma grande gama de informações. Assim, a referida autora acredita que cabe ao 
educador, nesta nova perspectiva, dar historicidade a este conhecimento e relacioná-lo com o contexto social e cultural.

Neste contexto, se faz necessária uma reflexão pedagógica que nos remeta aos sujeitos do campo, que nasça das práticas camponesas e se reflita na educação desenvolvida neste local e por estes sujeitos. Segundo Caldart (2002) "uma reflexão que reconheça o campo como lugar onde não apenas se reproduz, mas também produz pedagogia".

Caldart (2004) ainda afirma que "este projeto educativo pedagógico reafirma e dialoga com a pedagogia do oprimido, na sua instância de que são os oprimidos os sujeitos de sua própria educação, de sua própria libertação". Assim, a educação do campo deve ser cultivada pelos sujeitos do campo, através de sua organização e conforme sua necessidade.

Segundo Perin (2013), a educação do campo é um espaço propício para reflexões sobre interdisciplinaridade, uma vez que o próprio campo se caracteriza por uma diversidade cultural, social e econômica. Dar continuidade à educação do campo requer a análise das especificidades de cada lugar. Assim, compreender o lugar, enquanto categoria de análise da geografia, se faz de grande importância para o ensino-aprendizagem dos educandos e pode ser auxiliado pelo uso de tecnologias, como afirma Carvalho Sobrinho (2018).

O acesso a esta tecnologia democratiza o conhecimento dos educandos, segundo Rodrigues Junior e Cordenonsi (2014), as tecnologias de informação e comunicação surgem como potente instrumento de disseminação do conhecimento, democratizando o ensino e disseminando informações nas mais remotas regiões. Estas tecnologias viabilizam projetos educacionais organizados com base na integração da realidade na qual os sujeitos se inserem, bem como na organização administrativa.

Segundo Oliveira, Moura e Souza (2015), ao inserir as tecnologias nas escolas, é importante investir não só na formação de educadores para se adequarem às práticas tecnológicas, mas também, envolver todos que atuam na escola. Com o uso das tecnologias, educadores e educandos descrevem suas ideias, trocam experiências, produzem histórias e desenvolvem projetos que podem ser usados no cotidiano escolar (PERIN, 2013). 
Nesse sentido, o educador é fundamental para a prática desses projetos, pois, a qualidade educativa destas iniciativas depende do uso de sua didática, instigando o educando a pensar a teoria com a prática. À medida que o sistema educacional utiliza das tecnologias no processo de construção do conhecimento, há uma diminuição da exclusão digital e a educação ultrapassa as paredes da sala de aula, motivando os educandos com aulas dinâmicas interativas e diversificadas (PERIN, 2013).

Assim, segundo Seegger (2012), a alfabetização tecnológica do educador se faz de grande valia, pois é importante dominar a utilização pedagógica das tecnologias, de forma que elas facilitem a aprendizagem, e sejam objeto de conhecimento a ser democratizado para a construção de conhecimento. Segundo Sampaio e Leite (1999, p. 16) "Essa alfabetização tecnológica não pode ser compreendida apenas como o uso mecânico dos recursos tecnológicos, mas devem abranger também o domínio crítico da linguagem tecnológica".

Os avanços tecnológicos proporcionaram uma evolução no que se refere ao acesso aos meios de comunicação e informação, mudando assim, hábitos e comportamentos da população. A partir desse avanço, foram incorporadas novas formas de se relacionar, de pensar e de agir, o que modificou bastante as ações anteriormente rotineiras (VEIGA, 2010).

Nessa mesma linha de pensamento, Moreira (2000, p. 3) orienta que "a escola deve recorrer às tecnologias para construir novos ambientes de aprendizagem, o que implicará a construção de novos paradigmas educacionais com vistas à superação da sala de aula tradicional". Desta forma, as tecnologias de informação e comunicação são mediadoras pedagógicas e contribuem para a democratização da informação, promovendo um ensino mais dinâmico.

\section{Materiais e métodos}

Como aspectos metodológicos, a presente pesquisa se baseia em uma abordagem qualitativa, o que para Oliveira (2012) facilita descrever 
a complexidade de problemas e hipóteses, bem como analisar a interação entre variáveis, compreender e classificar determinados processos sociais, oferecer contribuições no processo das mudanças, criação ou formação de opiniões de comportamentos ou atitudes de indivíduos.

Deste modo, os procedimentos metodológicos consistem em realizar um estudo de caso, o qual, segundo Triviños (1987) tem por objetivo a análise profunda do estudo em relação a um objeto, uma unidade. $\mathrm{O}$ autor ainda ressalta que é um dos métodos mais relevantes de pesquisa qualitativa, e busca fornecer conhecimento acerca de uma realidade delimitada.

Após definida a abordagem que seria utilizada num segundo momento, houve o contato com a escola para a apresentação do projeto e escolha do período a ser aplicada a atividade. Após este contato foram realizadas as atividades com os educandos nas dependências da escola. A pesquisa foi realizada no período de agosto de 2016 a julho de 2017. Para tanto, foi utilizado o laboratório de informática, no qual se fez uso de projetor para demonstrar a atividade, e computadores com acesso à internet para a realização pelos educandos. O laboratório de informática conta com internet $W i$-fi, quatro (4) computadores em bom estado para uso e mais três (3) computadores que estão destinados para manutenção.

Participaram da pesquisa onze educandos na faixa etária entre 11 e 12 anos de idade, sendo cinco meninos e seis meninas. Todos estavam na mesma turma no ano de 2016 e 2017, no quinto e posteriormente sexto ano do Ensino Fundamental. A turma foi escolhida devido ao interesse da educadora regente da turma, bem como ao contato prévio estabelecido.

Foram realizados três encontros com esta turma. Um primeiro contato para a apresentação, posteriormente para falar sobre a questão ambiental e apresentar imagens de satélite e informações sobre o Google Maps. O terceiro encontro foi destinado a apresentar a ferramenta Google Maps e realizar um questionário, com perguntas abertas e fechadas.

Após o contato inicial com a turma e a apresentação da proposta, o segundo encontro teve como objetivo discutir sobre as questões ambientais. Foram trabalhados e discutidos os temas sobre desmatamento 
da mata ciliar e suas consequências para os rios. Para tanto, foram apresentadas imagens ilustrando o tema.

Vale ressaltar que estes conteúdos são de grande importância e estão presentes na Base Nacional Comum. A leitura do espaço, a visão crítica a partir dos mapas, as discussões sobre as questões ambientais são temas que devem ser desenvolvidos, como consta no texto da Base Nacional Comum:

A abordagem das relações espaciais e o consequente desenvolvimento do raciocínio espaço-temporal no ensino de Geografia devem favorecer a compreensão, pelos alunos, dos tempos sociais e da natureza e de suas relações com os espaços. A exploração das noções de espaço e tempo deve se dar por meio de diferentes linguagens, de forma a permitir que os alunos se tornem produtores e leitores de mapas dos mais variados lugares vividos, concebidos e percebidos (BRASIL, 2015).

Segundo os textos da Base Nacional Comum, é neste período do Ensino Fundamental que os educandos devem desenvolver habilidades, como o manuseio de mapas, bem como o uso de tecnologias. Estas habilidades ampliam o conhecimento e a facilidade nas áreas do conhecimento, especialmente a Geografia.

Sequencialmente, foram apresentadas imagens de satélite de rios nos quais a mata ciliar estava preservada, e comparado com imagens onde não existia mais a mata ciliar. Dessa forma, os educandos foram instigados a verificar, através da ferramenta Google Maps, se na comunidade de Arroio Grande a mata ciliar estava preservada.

$\mathrm{Na}$ terceira visita, foram apontados os dados sobre o Google Maps e exibida uma apresentação sobre a ferramenta. Nesta oportunidade, os educandos estavam agrupados em trios para usar a ferramenta no computador, conforme os ícones básicos da ferramenta eram explicados, eles iam manuseando a ferramenta nos seus respectivos computadores.

Depois desta atividade, as discussões foram mediadas pelos pesquisadores e pela educadora regente da classe sobre as transformações ocorridas nos últimos anos nas localidades onde os educandos vivem. 
Com o uso da ferramenta Google Maps, os educandos puderam ter uma visão mais ampla da realidade onde estão inseridos, passando por um processo de (re) conhecimento do lugar.

A partir da apresentação desta ferramenta e deste processo de(re) conhecimento do lugar, os educandos responderam ao questionário no qual identificaram quais as mudanças percebidas na sua comunidade, bem como a importância do uso de tecnologia para o aprendizado da Geografia. Optou-se por não divulgar o nome destes, sendo assim, as entrevistas se diferem através de números $(1,2,3 \ldots 11)$, que procedem a palavra "Educando". Exemplo: Educando 1.

\section{As potencialidades da ferramenta Google Maps na disciplina de Geografia na Escola Estadual de Ensino Fundamental Arroio Grande}

Durante a apresentação sobre a ferramenta Google Maps, os educandos iniciaram a utilização dos ícones básicos de localização do programa. No primeiro contato com o computador e com a ferramenta foi possível perceber que a maioria dos educandos tinham facilidade com o Google Maps.

Conforme os educandos foram conhecendo a ferramenta e observando a comunidade na qual vivem, os mesmos passaram por um processo de reconhecimento do lugar. Tudo o que eles observavam era considerado e destacado por eles, desde as ruas, as residências, até os rios, a mata, objeto de estudo naquele momento. Essas observações corroboram com as afirmativas de Carvalho Sobrinho (2018) e de Pandim (2006), os quais destacam que a tecnologia aliada à geografia é uma importante ferramenta para compreender o lugar de vivência dos educandos.

Assim, destaca-se as potencialidades do Google Maps enquanto um importante recurso para que os educandos compreendam o lugar e facilite a identificação de elementos expressos na imagem de satélite, como afirma os autores Rêgo e Serafim (2015). Estes pontos são observados quando os educandos destacam todos os detalhes encontrados nas imagens 
de satélite e sentem-se sujeitos pertencentes àquele lugar e parte daquele recurso, pois observam o lugar onde vivem e por vezes no recurso Street View, encontram alguns de seus colegas, vizinhos e familiares na imagem.

Ainda durante o terceiro encontro, conforme os educandos terminaram as atividades, os mesmos foram convidados a responder alguns questionamentos sobre a atividade. Assim, foi possível conhecer melhor a realidade destes educandos, bem como entender de forma concreta a experiência por eles obtida a partir da atividade proposta. Primeiramente, objetivou-se saber se os educandos conseguiram observar, identificar e localizar a área de estudo, no caso a comunidade de Arroio Grande. Todos os 11 educandos afirmam terem identificado a localidade onde vivem, bem como a escola.

Para estimular a leitura do espaço, os educandos pesquisaram no Google Maps se havia mata ciliar perto dos rios que escoam na comunidade. Vislumbrar as imagens de satélite despertou a curiosidade frente a esta temática e todos conseguiram identificar ao menos um problema ambiental, como o desmatamento e a erosão das encostas dos rios.

Questionados sobre a existência ou não de Áreas de Preservação Permanente, dois (2) educandos afirmaram que existe em todo o rio, o restante afirmou que existe em apenas alguns trechos, como realmente foi observado e apenas um (1) educando não soube responder. $\mathrm{O}$ uso do recurso possibilitou que todos os educandos percebessem como estavam as Áreas de Preservação Permanente. Alguns imaginavam que não haviam problemas ambientais como o desmatamento, enchentes e a ausência de mata ciliar, próximo de suas casas, em seu espaço de convívio.

Neste contexto, destaca-se que, na busca pela formação de um sujeito crítico, emancipado, faz-se essencial que estes minimamente tenham conhecimento dos problemas que afetam suas comunidades. No processo de construção do conhecimento pode-se partir dos problemas locais, relacionando os fenômenos a escalas maiores, possibilitando que o educando compreenda a realidade como um todo, tomando como referência seu espaço de vivência. Isto significa ir além e possibilitar que o educando (re)construa continuamente seus conhecimentos, a partir das diferentes perspectivas apresentadas ao longo de sua trajetória. 
Partindo desta compreensão, procurou-se desenvolver nos educandos uma visão crítica sobre os problemas que afetam a comunidade. A partir do momento em que passaram a utilizar, pesquisar no Google Maps e a identificar os problemas ambientais presentes, todos os educandos pontuaram que precisavam fazer algo para alertar a comunidade sobre o problema e mudar esta realidade. Ou seja, mudaram seu papel, passaram de expectadores a sujeitos do processo, tomando também para si a responsabilidade de modificar a realidade em que estão inseridos.

Ao visualizar as imagens de satélite, ao ver os rios, a mata, as residências, os educandos conseguiram compreender as noções básicas da cartografia e do espaço geográfico. Essas afirmativas vão ao encontro do que Dambrós (2014), propõe sobre o ensino da cartografia no âmbito escolar, o qual deve propiciar que o educando compreenda as questões ambientais que o circunda de forma mais clara.

O resultado obtido nos permite afirmar que o Google Maps é uma ferramenta que estimula a inteligência espacial, conforme afirmou Bottentuit Junior et al (2011). Isso se deve ao fato de que foi perceptível que os educandos foram estimulados a observar o ambiente a partir do uso dessa ferramenta.

Dessa maneira, pode-se perceber que o uso do Google Maps serve como uma importante fonte de pesquisa e pode ser utilizado como estratégia de ensino nas escolas para a alfabetização cartográfica, como afirma Castrogiovanni (2009). A importância desta ferramenta no ensino pode ser entendida a partir das falas dos educandos, "Ele serve para pesquisar, estudar e para se encontrar quando a gente se perder" (Educando 3).

No âmbito da geografia, o ensino de cartografia através de mapas digitais tem grande carga de informações e pode ser usado em diversos contextos. Como afirma Dambrós (2014), a imagem é a chave desse recurso, no qual o educador pode contextualizar com a realidade do educando, mostrar seu espaço. O site Google Maps contempla essa análise, pois torna visível o espaço para o educando.

Os educandos da escola de Arroio Grande pesquisados afirmaram ter acesso às TDIC, como computadores, celulares, tablets e rede de 
internet em sua maioria. Estes educandos ainda afirmam que possuem em suas residências a disponibilidade destes recursos, bem como a possibilidade de acessar computadores na escola. Esses dados vão de encontro e desmistificam a ideia de que o campo é sinônimo de atraso, Caldart (2004) afirma que o campo é lugar de conhecimento, onde não apenas se reproduz, mas se faz pedagogia.

Mesmo sendo uma pequena amostragem, as respostas nos permitem compreender que as tecnologias têm se difundido no meio rural. A visão de um camponês rude, atrasado, que não tem acesso à tecnologia não caracteriza os sujeitos do campo. Mesmo sendo apenas uma turma dentro de uma escola, a educadora regente da turma afirma que este é o padrão dos educandos da comunidade. A grande maioria possui acesso à tecnologia, nem que seja por um celular smartphone que possui acesso à internet ${ }^{2}$.

Ainda que os educandos possuam acesso a essas tecnologias, os mesmos relatam que não fazem sempre o uso destas, os pais restringem o acesso. Segundo eles: "Eu só uso de noite, prefiro ficar brincando do lado de fora" (Educando 6); "Uso quando está no meu horário de usar, mas prefiro brincar com meus cachorros" (Educando 11); "Sim uso, mas não todos os dias, prefiro andar de bicicleta" (Educando 2).

A partir dos dados coletados na pesquisa, verificou-se que existe um grupo de 4 educandos que afirmam raramente acessar a internet, mesmo tendo-a disponível em casa. Muitas podem ser as explicações, no entanto, esta discussão não estava entre os objetivos da pesquisa. No mais, podemos entender esta particularidade a partir do contexto e do lugar onde vivem os educandos, a liberdade e segurança que o meio rural oferece muito difere de centros urbanizados onde a macrocefalia urbana força o enclausuramento da população.

Assim, pode-se perceber que para a maioria dos educandos participantes da pesquisa, mesmo tendo acesso às TDIC, conciliam o uso de tecnologias com as atividades recreativas. Segundo eles, os sites mais acessados são aqueles que possibilitam a pesquisa escolar, que podem ser

2 Resposta concedida em conversa informal com a educadora regente da turma. 
acessados tanto na escola como em casa. Os que disponibilizam vídeos e músicas também são bastante frequentados, bem como redes sociais e sites com jogos.

Em relação ao acesso ao Google Maps, a maioria dos educandos relatou já possuir conhecimento dessa ferramenta. Para os que não conheciam, o contato foi positivo, como afirma o Educando 1 "Eu não conhecia ainda, mas amei a experiência". Essa afirmativa está em consonância com os apontamentos de Rêgo e Serafim (2015), quando indicam o Google Maps como uma importante ferramenta pois, instiga a curiosidade dos educandos.

Conforme relato dos educandos da escola de Arroio Grande, o uso da ferramenta Google Maps proporcionou este (re) conhecimento com a sua comunidade. Apesar da maioria da turma ter acesso à internet, alguns ainda não conheciam a ferramenta. Dos educandos que conheciam o Google Maps apenas um havia explorado a comunidade de Arroio Grande através do programa.

No entanto, todos afirmam conhecer o rio usado como exemplo, bem como toda a comunidade onde se insere. Esse conhecimento parte de um esforço da escola que preza por mostrar a realidade local para seus educandos. A educadora regente da classe afirma que são realizadas saídas a campo para conhecer a comunidade, o que mostra que esta escola preza por uma educação que seja do campo e para o campo.

A partir desse relato é possível perceber que a escola em questão cumpre com as Diretrizes Nacionais da Educação do Campo, na qual afirma que os conteúdos devem estar voltados para a realidade do lugar, valorizando seus costumes, hábitos e crenças.

Assim como enfatiza Molina e Sá (2012) e Caldart (2012), a educação do campo e a valorização dos sujeitos do campo é uma luta constante, a interação das TDIC se integra na luta no sentido de desmistificar a ideia de atraso no meio rural. A partir da pesquisa, se percebe que não há atraso, que a partir dos educandos participantes da pesquisa e segundo relato da educadora regente da turma, a tecnologia está difundida na comunidade. 


\section{Considerações finais}

A utilização do Google Maps como ferramenta no ensino de geografia proporcionou a criação de um ambiente de trabalho motivador, onde os educandos focalizaram a sua atenção, sentiram-se atraídos e estimulados na aprendizagem dos conteúdos e puderam relacioná-los com a sua realidade.

Ressalta-se a importância de utilizar esse tipo de ferramenta como mediadora na construção do conhecimento, tendo no educador o papel fundamental de incentivador e orientador da utilização das TDIC na educação. O educando pode ser conduzido a construir o seu próprio conhecimento, não restrito a conteúdos disciplinares, mas partindo do seu cotidiano, permitindo conhecer a si e ao mundo ao seu redor, tornando a aprendizagem significativa.

Através do uso do Google Maps, os educandos mostraram-se motivados em aula, bem como relataram que a ferramenta proporciona uma aprendizagem mais dinâmica e interativa, aproveitando conhecimentos prévios dos educandos, levando-os a relacionar os conhecimentos adquiridos com o seu cotidiano e tornando mais fácil o entendimento de conceitos mais específicos.

A partir desse contato com o Google Maps os educandos desenvolveram uma visão mais crítica sobre a questão ambiental, passaram por um processo de alfabetização cartográfica, desenvolveram interesse no estudo da Geografia, reconhecendo o lugar onde vivem.

Essas potencialidades mostram, a partir dessa pesquisa que o Google Maps é uma excelente ferramenta para se trabalhar a Geografia e a alfabetização cartográfica em sala de aula. Além de desmistificar a ideia de que em escolas do campo não é possível usar a tecnologia.

A pesquisa mostra que é possível e é importante o uso de tecnologia dentro de escolas do campo, uma vez que esta tecnologia já está difundida na realidade dos educandos fora de sala de aula. Ter acesso e usar a tecnologia em favor da educação é democratizar o ensino e a tecnologia. 


\section{Referências}

BRASIL. Base Nacional Comum 2015-2018. Disponível em:<http://basenacionalcomum.mec.gov.br/wp-content/uploads/2018/02/bncc-20dez-site.pdf > Acesso em: 28 maio 2018.

CANCELA. J. M. F. D. de Carvalho. O papel das TIC no desenvolvimento das competências transversais dos alunos. 2012. 141fl. Dissertação. Programa de Pós Graduação em Tecnologias de Informação e Comunicação e Educação, Universidade de Lisboa. Lisboa, 2012. Disponível em: <http://repositorio.ul.pt/ bitstream/10451/8253/1/ulfpie043263_tm.pdf >. acesso em: 30 de maio de 2018.

CALDART, R. S; KOLLING, E. J; CERIOLI, P. R. Educação do campo: identidade e políticas públicas. Brasília: Por Uma Educação do Campo, 2002. (Coleção Por Uma Nova Educação do Campo, nº 4). Parte II, p. 36.

CALDART, R. S. Pedagogia do Movimento Sem Terra. São Paulo: Expressão Popular, 2004.

CALDART, R. S. et al. Dicionário da Educação do Campo. Rio de Janeiro: Expressão Popular, 2012.

CARVALHO SOBRINHO, H. Geografia escolar e o lugar: a construção de conhecimentos no processo de ensinar/aprender geografia. Geosaberes, Fortaleza, v. 9, n. 17, p. 1-17, jan./abr. 2018.

CASTROGIOVANNI, A. Ensino de Geografia: práticas e textualizações no cotidiano. 7. ed. Porto Alegre: Mediação, 2009.

CORDENONSI, Andre Zanki; RODRIGUES JUNIOR, Alfredo Martins. O uso das tecnologias da informação e da comunicação como instrumento de democratização do direito à educação. Santa Maria, 2014. Disponível em: <http://repositorio.ufsm. br/handle/1/11366>. Acesso em: 30 mai. 2018.

CIROLINI, A. Atlas eletrônico e socioeconômico sob a perspectiva da cartografia escolar no município de Restinga Sêca, RS. 2008. 282 p. Dissertação (Mestrado e em Geografia) - Universidade Federal de Santa Maria, Santa Maria, RS, 2008. 
DAMBRÓS, G. Por uma cartografia escolar interativa: jogo digital para a alfabetização cartográfica no ensino fundamental. 2014.122 p. Dissertação (Mestrado em Geografia) — Universidade Federal de Santa Maria, Santa Maria, RS, 2014.

LEÃO, D. M. M. Paradigmas contemporâneos de educação: Escola Tradicional e Escola Construtivista. Cadernos de Pesquisa, n. 107, p. 187-206, jul. 1999. Disponível em <http://www.scielo.br/pdf/cp/n107/n107a08.pdf〉 Acesso em: 30 mai. 2018.

MEDEIROS, M. V; CABRAL, C. L. O. Formação docente: da teoria à prática, em uma abordagem sócio-histórica. Revista E-Curriculum, São Paulo, v. 1, n. 2, jun. 2006. Disponível em:<http://coral.ufsm.br/righi/EPE/MEDEIROS_CABRAL. pdf $>$. Acesso em: 30 mai. 2018.

MOLINA, M.C.; SÁ, L. M. Escola do Campo. In: CALDART, R. S. et al. Dicionário da Educação do Campo. Rio de Janeiro: Expressão Popular, 2012.

MOREIRA, V. Escola do futuro sedução ou inquietação: as novas tecnologias e o reencantamento da escola. Portugal: Porto Editora, 2000.

OLIVEIRA, M. M. Como fazer pesquisa qualitativa. 4. ed. Petropólis: Vozes, 2012.

OLIVEIRA, C.; MOURA, S. P.; SOUZA, E. R. TIC'S na educação: a utilização das tecnologias da informação e comunicação na aprendizagem do aluno. 2015. Disponível em:<http://periodicos.pucminas.br/index.php/pedagogiacao/article/viewFile/11019/88>. Acesso em: 19 nov. 2017.

PANDIM, A. R. Oficina pedagógica de cartografia: uma proposta metodológica para o ensino de geografia. 2006. 78 f. Graduação (Trabalho de Conclusão de Curso em Geografia) - Universidade Estadual de Londrina, Londrina, 2006.

PERIN, D. As tecnologias da informação e comunicação como facilitadoras da aprendizagem na educação do campo. Educação do campo, 12 dez. 2013. Disponível em:<http://edu-campo.blogspot.com.br/2013/12/as-tecnologias-da-informacao-e.html> Acesso em: 15 nov. 2017. 
RÊGO, E. E.; SERAFIM, M. L. A utilização dos aplicativos Google Maps e Google Earth no ensino de geografia: múltiplas possibilidades. In: CONEDU: CONGRESSO ESTADUAL DE EDUCAÇÃO, 2., 2015, Campina Grande. Anais... Campina Grande: Realize, 2015. Disponível em: <http://www.editorarealize.com.br/revistas/conedu/trabalhos/TRABALHO_EV045_MD1_SA4_ ID1946_08052015200043.pdf >. Acesso em: 20 mar. 2018.

SAMPAIO, M. N.; LEITE, L. S. Alfabetização tecnológica do professor. Petrópolis: Vozes, 1999.

SEEGGER, V.; CANES, S. E.; GARCIA, C. A. X. Estratégias tecnológicas na prática pedagógica. Monografias Ambientais, v. 8, n. 8, p. 1887-1899, ago. 2012.

TRIVIÑOS, A. N. S. Introdução à pesquisa em ciências sociais: a pesquisa qualitativa em educação. São Paulo: Atlas, 1987.

VEIGA, I. P. Didática: o ensino e suas relações. 15. ed. Campinas: Papirus, 2010.

VIGHI, C. S. B. Da escola na zona urbana para a escola do/no campo: os professores em foco. 2013. 128 f. Tese (Doutorado em Educação) - Programa de Pós-Graduação em Educação, Faculdade de Educação, Universidade Federal de Pelotas, Pelotas, 2013. Disponível em: <http://guaiaca.ufpel.edu.br/bitstream/ ri/2791/5/Da\%20escola\%20na\%20zona\%20urbana\%20para\%20a\%20escola\%20do\%20-\%20no\%20campo.pdf >. Acesso em: 3 jun. 2018.

Recebido: 02/08/2018

Received: 08/02/2018

Recibido: 02/08/2018

Aprovado: 10/09/2018 Approved: 09/10/2018 Aprobado: 10/09/2018 